\title{
BOOKS
}

\section{PEDIATRIC NUTRITION}

Textbook of Pediatric Nutrition, 2nd edn, edited by RM Suskind, L Lewinter-Suskind (1993). Raven Press, 1185 Avenue of the Americas, New York, NY 10036. 571 pages.

This second edition includes updated material and some new contributors; 62 authors have contributed to approximately 45 chapters and two appendices.

The book is divided into: infant nutrition, nutritional deficiency states, nutritional support of the hospitalized child and clinical nutrition. Current problems are addressed very well. The editorial style is different from chapter to chapter and some of them are overreferenced.

Although the publication date is 1993, very few chapters contain references beyond 1990. Most chapters contain appropriate and timely management strategies for nutritional interven- tion, but some are vague and incomplete. Overall, most subjects are well discussed, and the unit on nutritional support of the hospitalized child is welcome.

The classic nutritional disorders do not receive extensive coverage. Instead, the editors have significantly increased contributions about diseases and conditions more commonly seen in the clinical practice of pediatrics in North America. Caution is necessary for interpretation of some of the nutritional requirements and guidelines.

Overall this textbook is a welcome addition to pediatric textbooks for students, house officers and residents, as well as family physicians and general pediatricians.

Micheline Ste-Marie, MD, FRCPC Pediatric Gastroenterologist Izaak Walton Killam Children's Hospital Halifax, Nova Scotia

\section{CALENDAR OF EVENTS}

February 26-27, Los Angeles, California: Endoscopy 1994: Southern California Society for Gastrointestinal Endoscopy Symposium. Joyce M Fried, University of California at Los Angeles School of Medicine, Office of the Dean, 19833 Le Conte Avenue, Los Angeles, CA 90024-1722, USA, Fax (310) 2065046.

February 26 to March 5, Barbados, West Indes: Topics in Gastroenterology and Internal Medicine. Office of Continuing Medical Education, George Washington University Medical Center, 2300 K Street NW, Washington, DC 20037, USA, telephone (202) 994-4285, Fax (202) 994-1791.

March 19-22, Tel Aviv, Israel: Second International Conference on Gallstones: Causes and Management. Gallstone Conference Secretariat, Peltours-Te'um Congress Organizers, PO Box 8388, Jerusalem 91082, Israel. Telephone (97 2) 617 402, Fax (972) 637572.

April 16-19, Nashville, Tennessee: Society of American Gastrointestinal Endo- scopic Surgeons 1994 Scientific Session and Postgraduate Course. SAGES, 10111701 Texas Avenue, Los Angeles, CA 90025, USA, telephone (310) 479.3249, Fax (310) 479-9744.

August 14-19, Montreal, Quebec: 127th Annual Meeting of the Canadian Medical Association. CMA Meetings and Travel Department, PO Box 8650, Ottawa, Ontario K1G 0G8, telephone (613) 731-9331, Fax (613) 731-1779.

September 14-19, Toronto, Ontario: $63 \mathrm{rd}$ annual meeting of the Royal College of Physicians and Surgeons of Canada. Anna Lee Chabot, RCPSC, 774 Echo Drive, Ottawa, Ontario K1S 5N8, telephone 1-800-668-3740 or (613) 730 . 8177, Fax (613) 730-8830.

October 2-7, Los Angeles, California: World Congress of Gastroenterology 10th Quadrennial Celebration. Secretariat, World Congress of Gastroenterology, Suite 300, 655-15th Street NW, Washington, DC 20005, USA, telephone (202) 639-4626, Fax (202) 347-6109. 


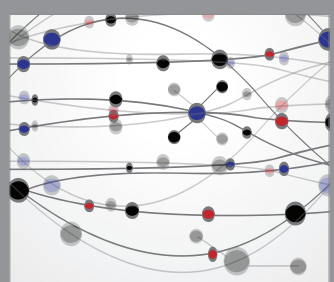

The Scientific World Journal
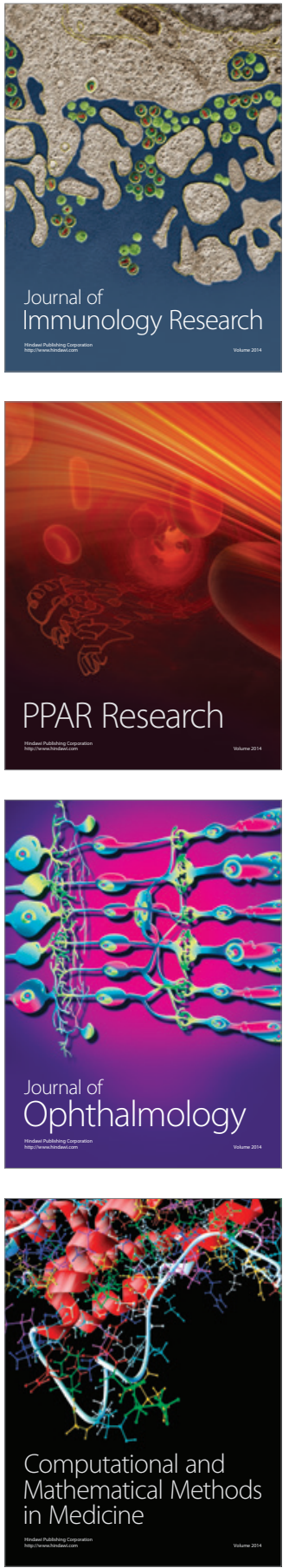

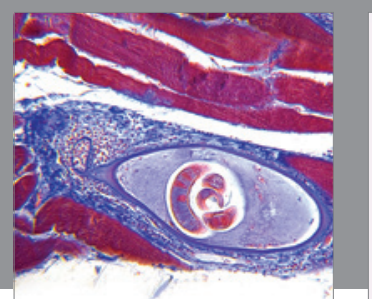

Gastroenterology Research and Practice

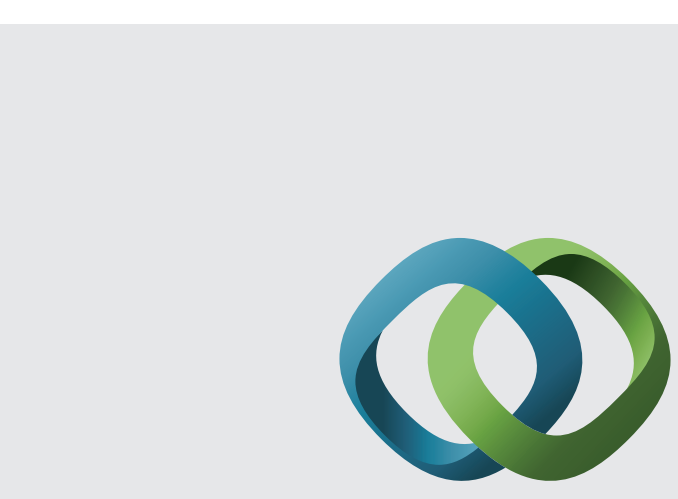

\section{Hindawi}

Submit your manuscripts at

http://www.hindawi.com
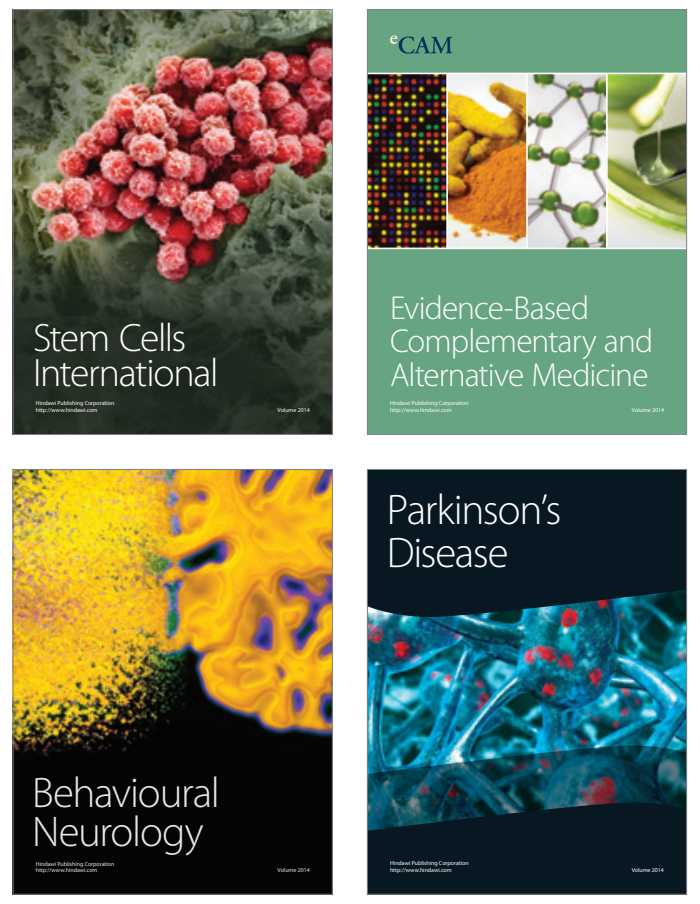
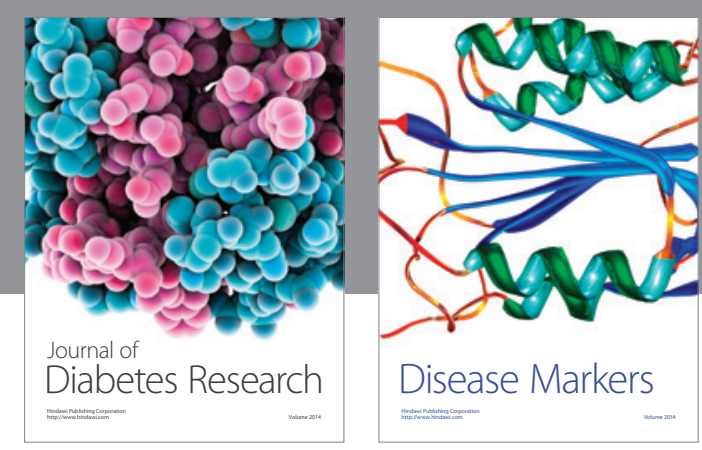

Disease Markers
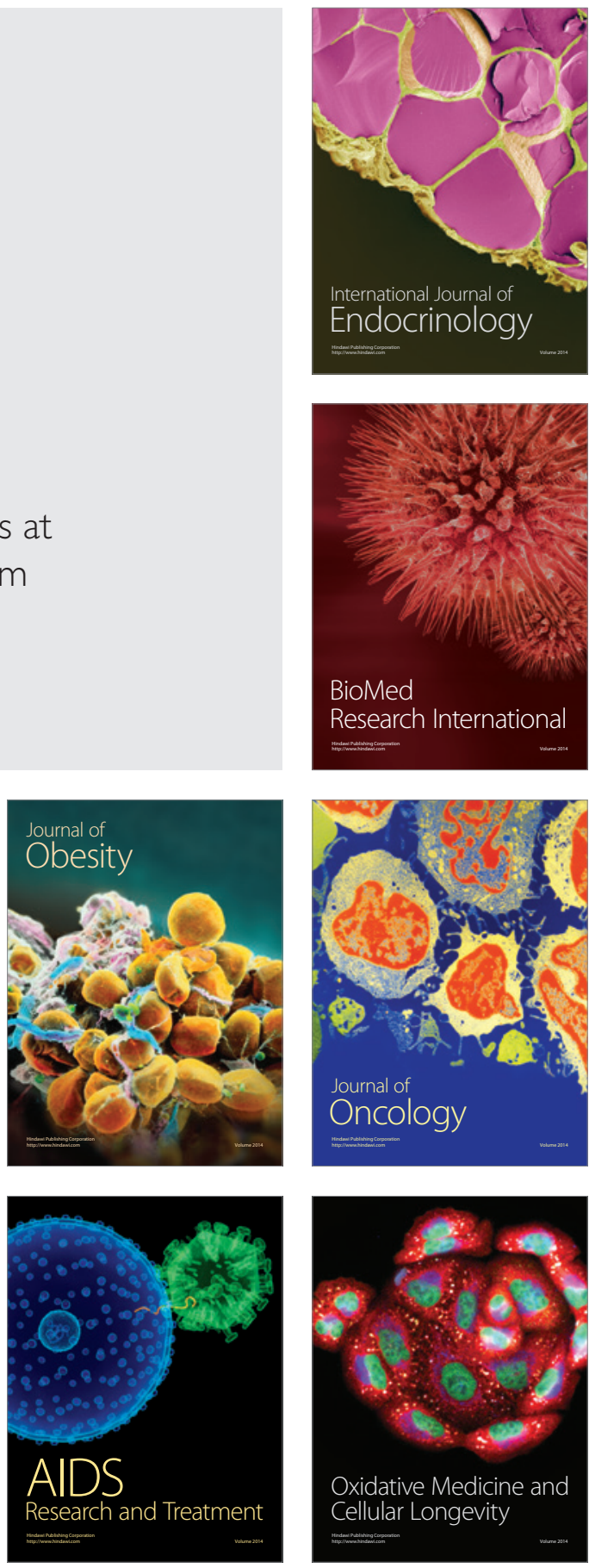